\title{
Review of modern concepts in the engineering interpretation of earthquake response spectra
}

\author{
A. Chandler, N. Lam, J. Wilson and G. Hutchinson
}

The design response spectrum is typically the starting point of most codified seismic design and assessment procedures and is used predominantly to prescribe the applied inertia forces induced by earthquake ground motions. This paper introduces and reviews modern concepts related to the effective development and application of earthquake design response spectra, including the conventional acceleration response spectrum, the velocity spectrum, and the displacement spectrum. It further briefly reviews the concepts of the inelastic response spectrum and the capacity spectrum. A number of the ideas presented are targeted particularly at assisting practising engineers working in low- and moderateseismicity environments. The principal purpose is to enlighten engineers to modern concepts in response spectra development, in order to subsequently facilitate the effective use of the information contained in an earthquake response spectrum for both analysis and design applications.

\section{NOTATION}

$\boldsymbol{A}, \boldsymbol{A}^{\mathrm{t}}$ response acceleration and total (absolute) response acceleration of single-degree-of-freedom (SDF) system to earthquake ground motion

$\boldsymbol{A}_{\mathrm{g}} \quad$ ground acceleration generated by an earthquake

C damping coefficient of SDF structural system

$C_{\mathrm{a}}, C_{\mathrm{v}}$ dual seismic coefficients used in UBC-97 seismic code in United States

$C_{\mathrm{cr}} \quad$ critical damping coefficient of SDF structural system

$D$ response displacement of SDF system to earthquake ground motion

EPGA effective peak ground acceleration, obtained as the peak RSA divided by $3 \cdot 0$

$E P G D$ effective peak ground displacement (the 5\% damped spectral displacement $D$, at $T_{\mathrm{e}}=5 \mathrm{~s}$ )

$E P G V$ effective peak ground velocity, obtained as the peak RSV divided by $2 \cdot 0$

g acceleration due to gravity $\left(=9 \cdot 81 \mathrm{~m} / \mathrm{s}^{2}\right)$

$H \quad$ total height of a building

$\boldsymbol{K} \quad$ lateral stiffness of SDF structure

$M \quad$ inertial mass of SDF structure participating in dynamic earthquake response; or earthquake magnitude

$P G A$ peak ground acceleration developed by an earthquake $P R S V$ pseudo response spectral velocity, derived from RSA or RSD
$\boldsymbol{R}$

seismic force (strength) reduction factor used in building codes

RSA response spectral acceleration

$R S D$ response spectral displacement

$R S V \quad$ response spectral velocity

$S \quad$ site factor defining spectral amplification of bedrock ground motions for soil sites

SDF single-degree-of-freedom dynamic structural system

$T$ fundamental natural period of dynamic SDF structural system

$T_{\mathrm{e}} \quad$ effective natural period of SDF structural system, used in defining the EPGD

$T_{1} \quad$ first corner period on earthquake response spectrum

$T_{2} \quad$ second corner period on earthquake response spectrum

$\boldsymbol{V}$ response velocity of SDF system to earthquake ground motion

critical damping ratio of SDF structural system $=C / C_{\mathrm{cr}}$

\section{INTRODUCTION}

Traditionally, a response spectrum prescribes the seismicallyinduced inertia forces to be applied when designing a structure. Response spectra have also been used to prescribe other seismically-induced effects such as the velocity (related to kinetic energy) and, more recently, displacement (determining the structural interstorey drifts and deformations). The original concept was limited to elastic response parameters (forces and deformations) but, since the 1960s, has been extended to account for inelastic yielding response of structures subject to extreme design seismic loadings. ${ }^{1,2}$

Some of the basic principles presented in this paper are well understood within earthquake engineering research circles, while certain ideas have not been widely recognised. On the whole, the materials presented in this paper will not be familiar to most practising engineers, particularly those working in lowand moderate-seismicity environments. The objective is to enlighten practising engineers on certain key modern concepts, in order for them to make effective use of the information contained in an earthquake response spectrum, for both analysis and design applications. Understanding the issues and concepts presented in this paper is a prerequisite to understanding the problems related to development of these response spectra for a given subject region, which is an issue addressed in a companion paper. ${ }^{3}$ 
The materials contained in the present paper are presented in a simple conceptual format, while the mathematical rigour, as commonly found in formal text books on this subject, ${ }^{1}$ has been omitted for easy reading. The following section of the paper presents the conventional acceleration response spectrum, which is related directly to the inertia force developed in a structure according to Newton's second law of motion. It is emphasised that the major limitation of this procedure is that the inertia force is strictly applicable only to elastic responding structures. Contemporary codes of practice ${ }^{4}$ have attempted to overcome this problem by introducing empirical response reduction factors (often termed $R$-factors) to allow for inelastic behaviour, as referred to later. However, such a conventional force-based (FB) approach suffers further severe limitations, as it does not directly address the potential seismic performance of a structure (in relation to the design objectives), and this paper also highlights such deficiencies.

Section 4 presents the displacement response spectrum, which directly addresses the deformation of a structure responding to earthquake ground motions. The deformation is, in turn, directly related to performance and the state of damage to both structural and non-structural components. However, the displacement spectrum is not without its limitations, and its potential can be greatly enhanced by the associated use of the velocity response spectrum, which is described in the Sections. This section presents the velocity spectrum in the common tripartite form, and indicates how the spectral velocity provides estimates for the seismically induced maximum kinetic energy (KE) which can be used to check against the energy absorption capacity of an inelastic responding, and strength-deteriorating structure. Although the kinetic energy was strictly derived from elastic responses, the elastic velocity response spectrum can be used to obtain conservative estimates of kinetic energy developed in non-linear systems. Similarly, although the displacement spectrum is strictly derived in accordance with responses of elastic systems, several procedures have been developed to extend the capability of the displacement spectrum for the analyses of inelastic systems. These procedures are reviewed in Reference 5 and the code implications are addressed in Reference 6 . Among the procedures is the concept of the capacity spectrum (CS), which was evolved from the displacement concept, and, in Section 6, this paper briefly introduces the CS concept along with other methods for deriving information on the inelastic seismic demands and capacity of structural systems.

\section{FUNDAMENTALS OF EARTHQUAKE ACCELERATION RESPONSE SPECTRUM}

In conventional earthquakeresistant (seismic) design of structures, the structural effects of an earthquake are represented by equivalent horizontal inertia forces. This is termed the force-based (FB) method of seismic design and forms the basis of essentially all seismic loadings codes. ${ }^{4,7}$ From the fundamental concept of dynamics known as Newton's second law of motion, ${ }^{1}$ the earthquake-induced horizontal (lateral) forces acting on a structure are obtained simply by the multiplication of the structure's inertial mass $(M)$ and the horizontal acceleration of this mass, where the latter varies with time according to the accelerations induced by ground movements. The contributory inertial mass of a building arises from its self-weight (such as the floors, walls, beams and columns in steel or concrete) with an additional weight allowance due to non-structural partitions, furniture, equipment and occupants. In a historical context, ${ }^{1}$ engineers have worked with the peak ground accelerations (PGAs) arising from the earthquake, to calculate the peak inertia force used in conventional FB seismic design. The PGA represents the peak elastic response (spectral) acceleration (RSA) of the mass, when the structure supporting the mass is so rigid that the mass undergoes movements which are similar to those of the ground, as illustrated in Fig. 1(a).

Taking account of the actual stiffness $(\boldsymbol{K})$ of the structure, the increased flexibility compared with the idealised rigid case leads to dynamic modifications of the response acceleration and the associated inertia force. Using a simple acceleration pulse (Fig. 2(a)) as an example, the influence of a gradual reduction in stiffness of an initially 'rigid' structure on the resulting RSA of the structure has been illustrated (Fig. 2(b)). For systems that are effectively rigid (infinite stiffness $\boldsymbol{K}$ ), the RSA equals the maximum 'input' acceleration or PGA. Then, there is initially an amplification of the response acceleration as the structure stiffness gradually reduces (and hence $1 / \boldsymbol{K}$ increases), until RSA reaches some peak value. This peak response reflects the maximum inertial force that can be developed on the structure, and occurs when the interaction between the dynamic properties of the structure and the dynamic energy input arising from the acceleration pulse is at a maximum. For the pulse problem, a further decrease of stiffness (increase in $1 / \boldsymbol{K}$ ) results in decreasing RSA (Fig. $2($ b)) as the structural system becomes less sensitive to dynamic excitation arising from the pulse. Theoretically, RSA converges to zero as the stiffness is reduced to zero, as no force is then transmitted to the structure and its absolute motion is static (Fig. 1(b)). 


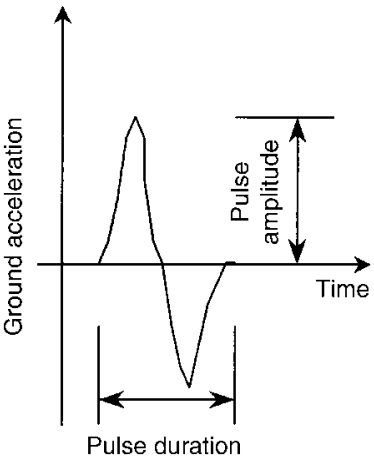

Pulse duration

(a)

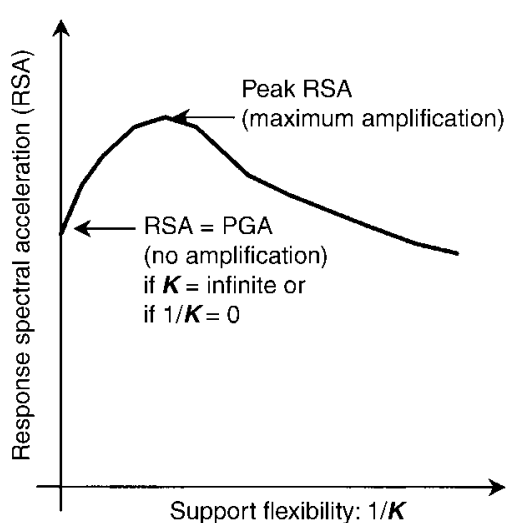

(b)

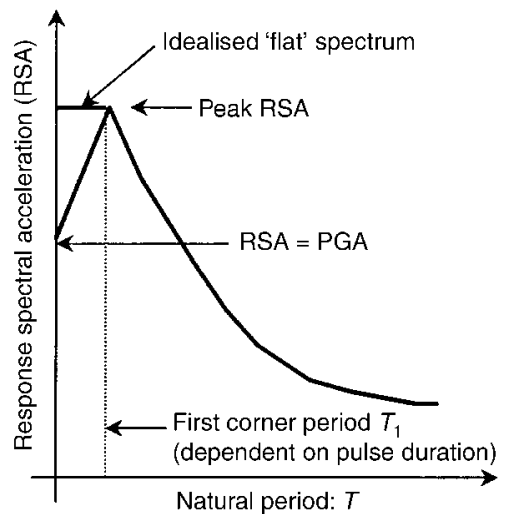

(c)

Fig. 2. Response spectral acceleration of a ground acceleration pulse: (a) ground acceleration pulse; (b) RSA plotted against I/K; and (c) RSA plotted against $T$ (acceleration response spectrum)

In the foregoing example, the controlling parameter for the response behaviour of the structure is not simply the stiffness $\boldsymbol{K}$, but the ratio $M / \boldsymbol{K}$. For two systems, if the ratio $M / \boldsymbol{K}$ is a constant, then their dynamic response is identical, assuming equal rates of energy dissipation (damping) arising from the dynamic motion. This ratio is related directly to the natural fundamental period of free vibration of the structure $T$, where $T=2 \pi \sqrt{ }(M / K)$. Hence, the conventional form of RSA is to plot this parameter against the period $T$ (Fig. 2(c)). When $T=0$ (infinitely rigid system), then RSA = PGA, as before. The peak RSA occurs at what is termed the first corner period, $T_{1}$. The ratio of the peak RSA to the PGA is dependent on the system's level of structural damping. A typical shape of an acceleration response spectrum (RSA spectrum), arising from an acceleration pulse, is illustrated in Fig. 2(c), which indicates the peak RSA and the corner period $T_{1}$. Next, consider the situation as the duration of the pulse is allowed gradually to increase, and the shape of the response spectrum changes accordingly. The corner period is gradually shifted to the right (to longer period values) as the pulse duration increases, as longer period structural systems become more sensitive to the lower frequency energy imparted by the pulse.

Earthquake ground motions may be appropriately described as a series of individual acceleration pulses, ${ }^{1}$ rather than a single pulse. The individual pulses generate instantaneous inertia forces in the structure. The energy and hence dynamic motion of a system in response to the earthquake ground motion is comprised of the accumulation of responses to these individual pulse inputs. The resulting earthquake response spectrum gives an indication of the average pulse duration, since the period range over which the RSA peaks will coincide with the dominant period of the ground motion input. The upper limit of the period range over which RSA peaks (i.e. the start of the reduction of RSA as the period further increases) has a close relationship with the corner period $T_{1}$ of the spectrum. The dominant period of the ground motion also strongly reflects the site soil condition, being shorter for rock-like conditions and increasing with the overall softness of any site soil layer overlying the bedrock. ${ }^{7}$ Earthquake design $\operatorname{codes}^{4}$ specify the corner period $T_{1}$ to be in the range $0 \cdot 2-0 \cdot 25 \mathrm{~s}$ for rock sites, increasing to around $0 \cdot 3-0.5 \mathrm{~s}$ for stiff to intermediate soil sites (such as moderately stiff sands and gravels of shallow to intermediate depths) and to $0 \cdot 6-1 \cdot 0 \mathrm{~s}$ for softer soils such as deep sands and sites containing soft or very soft clay deposits. Nevertheless, even for an individual site on bedrock, it has been recognised $^{8,9}$ that the response spectrum, and in particular the corner period, may vary a great deal depending on the size (magnitude) of the earthquake and its epicentral distance from the site location. In fact, recent research and seismological modelling has indicated that earthquakes occurring in a low to moderately active seismic area such as eastern North America (ENA) typically possess shorter pulse durations than their western North America (WNA) counterparts. ${ }^{10,11}$ From recent analyses by the authors of a large number of actual and synthetically generated earthquake records in a variety of seismo-tectonic conditions, the corner period $T_{1}$ has been found to have values ranging between around $0 \cdot 1-0.5 \mathrm{~s}$, for bedrock ground motions. ${ }^{8}$ Such variations have to date not been incorporated in code design spectra. In fact, seismic design forces designated by codes are often based on fairly restrictive assumptions. For example, many earthquake loading standards developed worldwide ${ }^{4}$ actually originated from early editions of the United States Uniform Building Code (UBC), ${ }^{12}$ and hence many of the loading provisions specified in these standards have effectively been developed primarily from the observed characteristics of earthquake ground motions in California (with WNA generic characteristics).

The acceleration (RSA) response spectrum is recognised to be a very effective and direct way of representing the highly variable properties of the earthquake ground motion. The RSA can identify what types of structure (within a particular range of natural period) are most strongly affected by a given earthquake ground motion. Taking the generic RSA spectrum shape indicated in Fig. 2(c), earthquake design standards and $\operatorname{codes}^{4}$ have specified a typical flat-hyperbolic elastic spectrum as the basis of seismic design, as shown for example in Fig. 3 


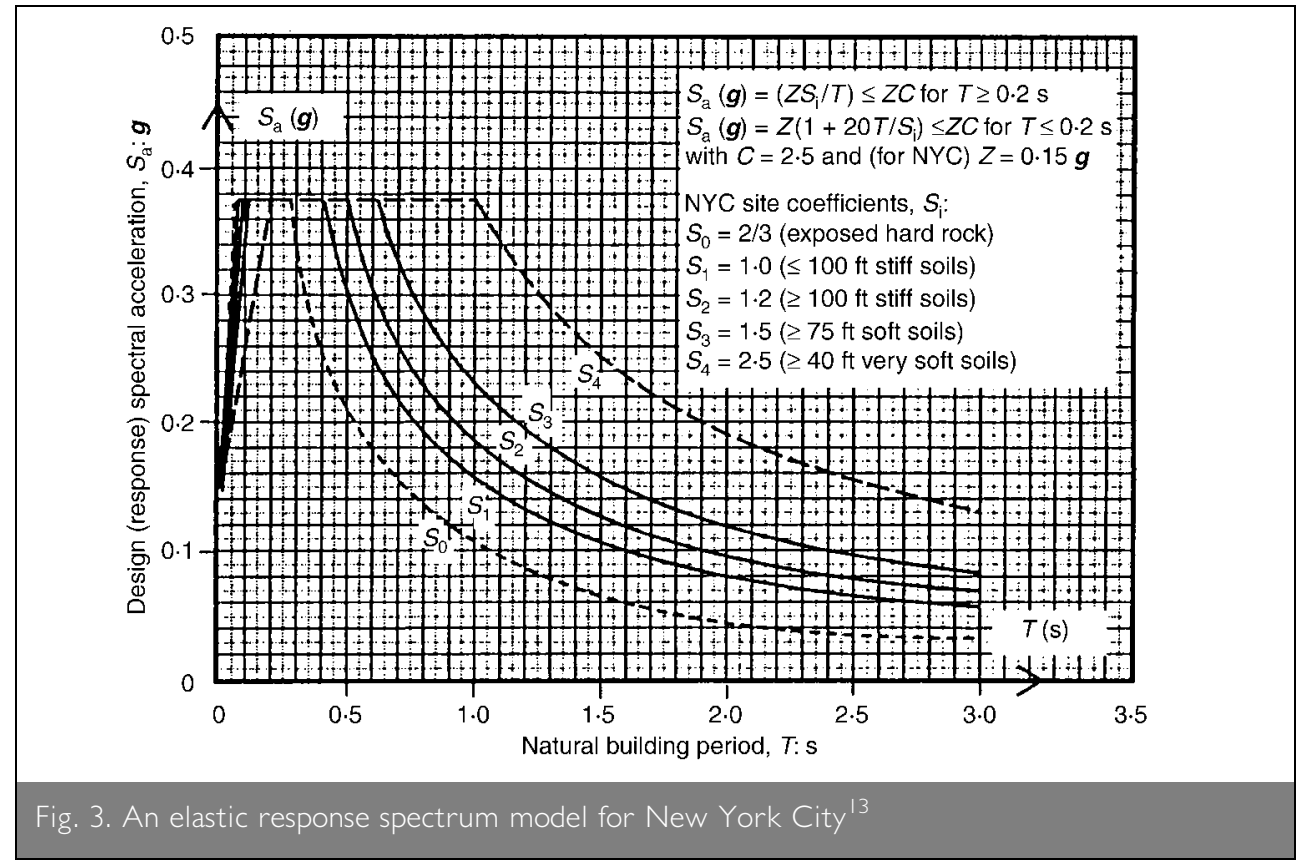

response acceleration $(\boldsymbol{A})$, velocity $(\boldsymbol{V})$ and displacement $(D)$ are related to the system's properties ( $\boldsymbol{K}, M$ and the damping coefficient $C$ ) by the following relationships

la $M \boldsymbol{A}+C \boldsymbol{V}+\boldsymbol{K} D=-M \boldsymbol{A}_{\mathrm{g}}$

or

\section{Ib $\quad M A^{\mathrm{t}}+C \boldsymbol{V}+\boldsymbol{K} D=0$}

The term $\boldsymbol{A}_{\mathrm{g}}$ represents the time-varying ground acceleration $\left(P G A=\max \left(\boldsymbol{A}_{\mathrm{g}}\right)\right)$, while $\boldsymbol{A}^{\mathrm{t}}$ is the total (absolute) acceleration of the structure mass $M$, given by $\boldsymbol{A}+\boldsymbol{A}_{\mathrm{g}}$. The critical damping is given by $C_{\text {cr }}=2 \sqrt{ }(\boldsymbol{K} M)$, and the

for the 1995 edition of the seismic code introduced in New York City (in ENA). ${ }^{13}$ The initial, short-period rising part of the spectrum is generally of little consequence for most structures, since few have natural periods below $0 \cdot 1 \mathrm{~s}$. The design acceleration spectra stipulated by $\operatorname{codes}^{4,7}$ also incorporate site $(S)$ factors, as in Fig. 3, which modify the corner period $T_{1}$ to reflect the predominantly longer-period ground motion properties on soil sites. The site factor $S$ effectively designates the ratio of RSAs in the medium to long period ranges, referred to the case with $S=1 \cdot 0$ which generally represents a soft rock or very stiff soil condition. Hence, the site factors have been used by code drafters to modify a rock spectrum in accordance with the site classification.

The ratio of the peak RSA (flat part of the design acceleration spectrum) to the PGA (=RSA at zero period) is known as the acceleration amplification factor and is typically $\sim 2 \cdot 0-3.5$ for individual earthquake records, the value 2.5 being generally assumed by codes. ${ }^{4}$ In fact, this ratio is dependent on the level of energy dissipation or structural damping, ${ }^{1}$ with the majority of engineering structures possessing damping for moderateamplitude dynamic motions in the range $2-5 \%$ of critical damping. ${ }^{14}$ In most code design spectra, 5\% of critical damping has normally been assumed. For systems with higher or lower damping, the appropriate amplification factors have been specified according to analysis of a large number of actual earthquake records, ${ }^{14}$ and this enables the factor to be specified probabilistically at median or median plus standard deviation design levels. The recently introduced European seismic design code EC $8{ }^{15}$ incorporates an explicit modification factor which accounts for damping levels which deviate from the assumed benchmark level (5\% of critical).

\section{DISPLACEMENT RESPONSE SPECTRUM}

Notwithstanding the foregoing discussion, it should be acknowledged that earthquake ground motions actually induce displacements in a structure, rather than externally applied forces. According to the dynamic equation of motion of a single-degree-of-freedom (SDF) structural system when subject to earthquake base (ground) motions, ${ }^{1}$ the time-varying critical damping ratio referred to earlier is then designated by $\zeta=C / C_{\mathrm{cr}}$. It is noted that the RSA is given by $\left(\boldsymbol{A}^{\mathrm{t}}\right)_{\max }$, and correspondingly the response spectral velocity $R S V=(\boldsymbol{V})_{\max }$ and the response spectral displacement $R S D=(D)_{\text {max }}$. From the assumption that the dynamic earthquake response at any time instant may be taken as equivalent to simple harmonic motion of an SDF oscillator, ${ }^{1}$ it may be deduced that at the same time instant that the displacement response $D$ reaches its maximum value $(D)_{\max }=R S D$ (when $\boldsymbol{V}=0$ ), the acceleration response $\boldsymbol{A}^{\mathrm{t}}=\left(\boldsymbol{A}^{\mathrm{t}}\right)_{\max }=R S A$. For a system with natural period $T$ (in seconds), it is further deduced that the following relationship exists between $R S D$ and $R S A$

\begin{tabular}{|l|l|}
\hline 2 & $R S D=(M / K) R S A=\frac{R S A}{\left(\frac{2 \pi}{T}\right)^{2}}$ \\
\hline
\end{tabular}

The earthquake response displacement ( $D$ or $R S D$ ) of an SDF system has a simple relationship with that of a multi-storey building of typical frame or frame-wall construction. ${ }^{16}$ In fact the RSD may be equated, for indicative purposes, simply to the peak lateral earthquake displacement of such a multi-storey building, taken at its effective height. In Reference 16, Priestley shows that for buildings experiencing a ductile beam-sway mechanism (which is regarded as a fundamental design objective for ultimate limit state design earthquake ground motions in the US, ${ }^{12}$ New Zealand ${ }^{17}$ and European ${ }^{15}$ seismic design codes, based on the 'capacity design' concept), ${ }^{18}$ the effective height is about $0 \cdot 64 \mathrm{H}$ (very close to two-thirds of the total height $H$ of the building). The effective height has also been derived for the soft storey column-sway mechanism. These two cases are illustrated in Fig. 4. For a more rigorous derivation of the relationship between the displacement of an SDF system and the storey drift of a multi-storey building, refer to Reference 19.

Due to the simplified relationship between the displacement response predicted by a simple SDF analysis (based on the RSD) and the drift pattern of a multi-storey building under seismic loading, researchers have introduced the concepts of the effective (secant) stiffness, the effective mass and the effective 
natural period of a substitute structure (Fig. 5), as reviewed in Reference 19 and applied in Reference 20, for example, to seismic structural assessment for intraplate regions. The elastic RSD spectrum may be employed to predict the inelastic drift behaviour of a building, using such concepts. The equivalent viscous damping has accordingly been increased to emulate hysteretic energy dissipated in the system as a result of ductile yielding in various mechanisms (Fig. 4) when severe earthquake loading occurs. ${ }^{19}$ Such an approach has the advantage that it offers a straightforward means of estimating and checking the overall seismic performance of the building structure by comparing the predicted drift against the permissible drift limits. The New Zealand Standard ${ }^{17}$ and associated literature state explicit limits defining various levels of performance, and the use of such guidelines is becoming increasingly commonplace in seismic engineering practice worldwide. ${ }^{21}$ Hence performancebased (PB) structural evaluation and design ${ }^{5}$ focuses on ensuring acceptable structural performance at a target ultimate displacement, rather than on initial elastic stiffness and strength as in the traditional FB method.

Underlying the tendency, since the mid-1990s, for earthquake engineering practice to move increasingly towards the use of DB (displacement-based) and PB seismic design concepts and approaches, has been the recognition (amply supported by evidence from post-earthquake field investigations following several major events of the past 20 years) ${ }^{22}$ that seismic displacement (which is related to deformation, strain, and drift) more directly addresses the seismic performance of a structure than do the response spectral accelerations. Crucially, the survival capability of a structure is more a function of its displacement capacity rather than its initial yield strength. The peak displacement demands (represented by the RSD) are closely linked to damage to non-structural as well as structural elements, and for inelastic response may be used to predict the overall ductility demands imposed on the structural elements. ${ }^{19}$

The characteristic shape of the displacement response spectrum may be deduced by considering the dynamical principles of a simple physical experiment which an SDF system comprising a trolley of mass $M$ resting on 'frictionless' wheels and connected by a spring of stiffness $\boldsymbol{K}$ to a fixed wall is excited at its base by simulated earthquake ground motions (Fig. 6). For present purposes, the damping of such a system is neglected. Initially, for very stiff systems having a very short natural period, the RSD is very nearly zero; that is, if the spring $\boldsymbol{K}$ is very stiff, the movement of the trolley relative to its base support is negligible. As before, to simulate the increasing natural period of the system, the spring is considered to have a gradually reducing stiffness $(\boldsymbol{K})$ or the trolley is considered to have an increasing inertial mass $(M)$. Now, consider typical earthquake ground motions on rock sites as discussed earlier. In the acceleration-controlled natural period range (approximately less than $0 \cdot 2 \mathrm{~s}$ ), the RSD is found to increase approximately parabolically with increasing natural period (Fig. 7(a)). In the velocity-controlled period range $(\sim 0 \cdot 2-1 \cdot 0 \mathrm{~s}$, typically), the RSD increases approximately linearly with increasing natural period until it levels off at a threshold limit which is the peak ground displacement (PGD). The reasons for the parabolic and linear behaviour will be explained in the next section, based on 


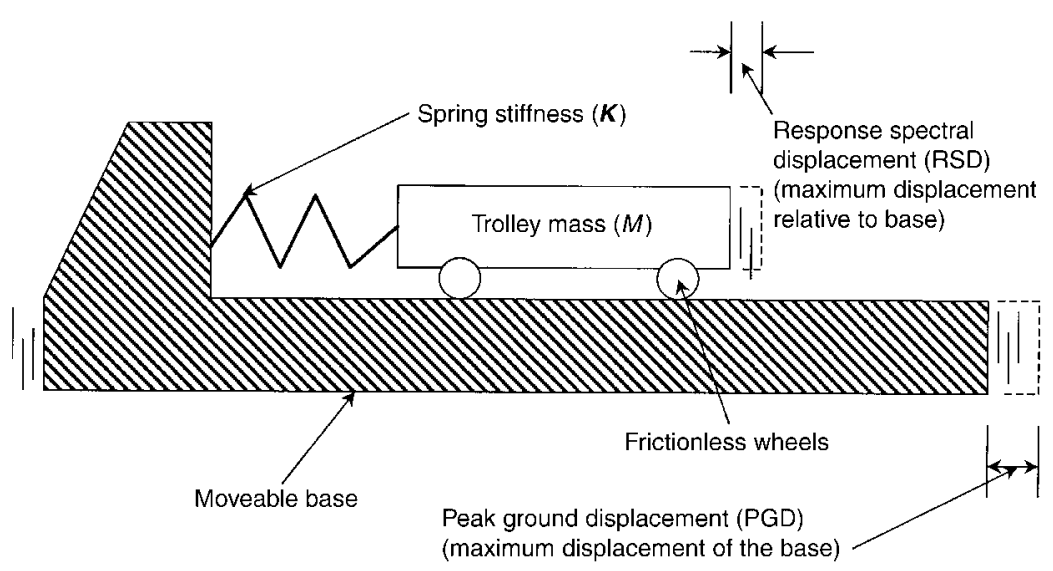

Fig. 6. Trolley experiment illustrating the behaviour of response spectral displacement

displacement demand is generally small and the period of convergence can be under $1 \mathrm{~s}$ (Fig. 7(a)). In contrast, for events having very large magnitudes $(M>7)$, the period of convergence is generally around 3-6s, but in some instances can exceed $10 \mathrm{~s}$ (Fig. 7(a)). This issue has been evaluated in detail elsewhere. ${ }^{8,9,25,26}$ Narrow-band amplification of earthquake RSD spectra may be expected to occur for records taken from soft soil sites. The period range in which this occurs may be $\sim 0.5-2 \mathrm{~s}$, depending

interpretation of the tripartite form of the earthquake response spectrum. ${ }^{14}$ The threshold region of the spectrum, for which the $\mathrm{RSD}=\mathrm{PGD}$, may be justified in the physical model (Fig. 6) by considering the spring to be disconnected from the trolley, thereby simulating a long-period system with very low stiffness, such as a tall building or a bridge supported on very flexible piers. Obviously, if the wheels supporting the trolley are frictionless, the relative displacement of the trolley compared with its base support naturally equals the applied displacement at the base. In effect, the base movement cannot be transmitted into the structure and its absolute motion is zero.

The natural period at which the RSD converges to the PGD has been found to vary considerably among different earthquake records. ${ }^{23,24}$ Among other parameters, this so-called corner period or period of convergence, $T_{2}$ (as distinguished from the corner period $T_{1}$ in the RSA spectrum) depends strongly on the magnitude $M$ of the earthquake. For $M=5$, representing approximately the threshold for engineering damage, ${ }^{2}$ the on the depth and stiffness of the soil deposits (Fig. 7(b)).

In theory, as previously discussed, the very long-period threshold limit of the RSD (allowing the natural period of the structure to increase indefinitely) is equal to the PGD. This may occur at periods around $10 \mathrm{~s}$ or more, especially for large magnitude earthquakes. However, it is of practical significance that the effective natural period of the majority of structures rarely exceeds $3-5 \mathrm{~s}$, even if significant yielding has taken place. Hence, the use of the PGD to define the displacement demand for structures with various natural periods is not always appropriate. To resolve this, the effective peak ground displacement (EPGD) has been defined here as the maximum RSD of an SDF system with a critical damping ratio of 5\%, taken within the period range up to the maximum considered effective natural period, $T_{\mathrm{e}}$. The value of $T_{\mathrm{e}}$ has been fairly arbitrarily defined herein as $5 \mathrm{~s}$, corresponding to the approximate upper limit of effective structural periods for normal structures, as referred to earlier. The effective damping ratio of $5 \%$ is in agreement with that assumed in seismic codes,

although it probably underestimates the actual effective damping of yielding structural systems and hence introduces a further element of conservatism in the evaluation of seismic displacement demands.

In using equation (2), if the RSA is taken to be of the standard flat-hyperbolic form as illustrated in Fig. 2(c), then it is observed that in the long-period range, the RSD will increase linearly (without limit) with period $T$, and hence such a procedure will inevitably lead to a grossly overconservative estimate of spectral displacements for long period systems. Thus, the drift, or displacement, of flexible 
structures possessing long to very long natural periods ( $>2$ s) are often overpredicted by the conventional FB procedure using standard acceleration response spectra.

The foregoing difficulties in accurately modelling the RSD spectrum for DB design purposes have, in the past, been greatly compounded due to the generally poor resolution of ground motion accelerometers in the long period range. However, more recent systematic studies have employed base-line corrections and filters to extract the low-frequency information from accelerograms, and useful observations have been made with regard to response spectral displacement properties. $^{23,24}$

\section{PSEUDO-SPECTRAL VELOCITY AND VELOCITY RESPONSE SPECTRUM}

In a manner similar to that described by equation (2), the pseudo response spectral velocity (PRSV) may be obtained from

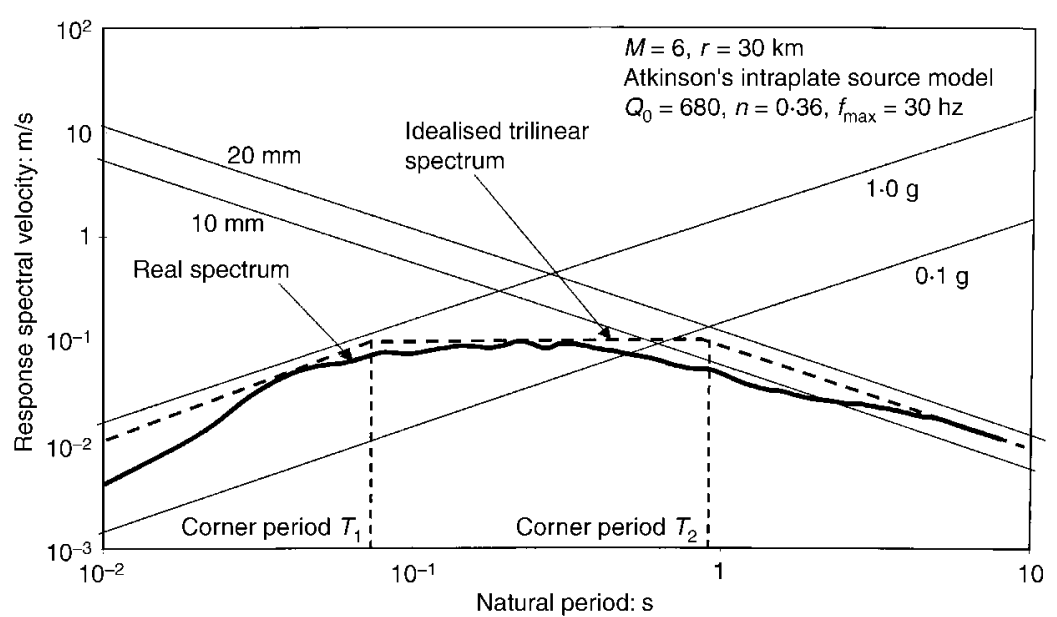

(a)

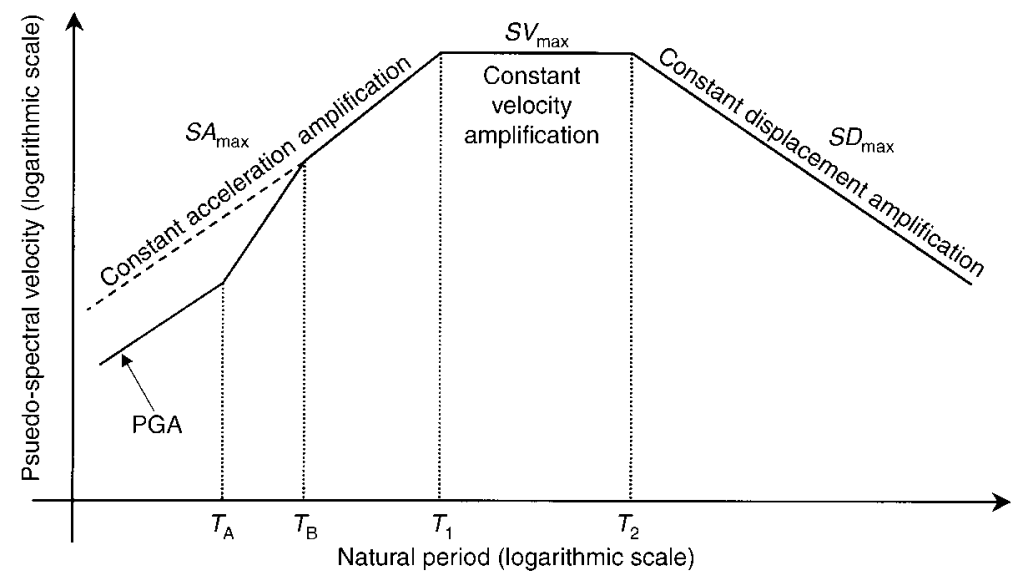

(b)

Fig. 8. Diagrammatic representation of: (a) a typical response spectrum on a rock site in a tripartite form; ${ }^{8}$ and (b) comparison of tripartite spectrum models (Table I refers)

$3 \quad P R S V=\frac{R S A}{\frac{2 \pi}{T}}$

The description 'pseudo' is employed to distinguish this response velocity from the actual response velocity of the system (measured relative to the ground or support), although the two response parameters differ by only small amounts in the period range covered by most real structural systems. ${ }^{1}$ Hence, in this paper, PRSV is assumed equivalent to RSV. Reference 1 gives a detailed description of the tripartite response spectrum, which is a convenient format for graphically presenting RSA, RSV and RSD, using diagonal logarithmic scales for the first and last of these parameters. The general form of such a spectrum has been illustrated in Fig. 8(a), which indicates that the tripartite spectrum of a typical (simulated) earthquake record may be idealised into the trilinear form, by introducing the two corner periods $T_{1}$ and $T_{2}$ as defined earlier. Design spectra in codes ${ }^{4}$ have conventionally been presented only in the form of RSA, and hence tripartite spectra have found applications mainly in presenting the response spectral information of individual earthquake records across a wide period range. The tripartite response spectra generalised as in Fig. 8(b) presented in the CAM (component attenuation model) procedure as newly developed by the authors, ${ }^{8,9}$ which is fully discussed in the companion paper, ${ }^{3}$ along with those of Somerville et al. ${ }^{27}$ for intraplate bedrock sites, have been compared in Table 1 with the standardised response spectrum model presented by Newmark and Hall ${ }^{14}$ for averaged 'Californian conditions'. Table 1 compares the key parameters defining the response spectra. Salient features are briefly described and commented upon as follows.

(a) A constant amplified maximum RSA ( $=S A_{\max }$ ) occurs for $T<T_{1}$ which is $\sim 0 \cdot 1-0.5 \mathrm{~s}$. $S A_{\max }$ is about two to three times the PGA, according to the various models. The conservatism evident in the Lam et al. model, in relation to the other models, has been explained in References 8 and 9, which present the detailed derivation of the seismologically based CAM approach.

(b) The response spectral accelerations converge to PGA as the natural period approaches zero, except for the Lam et al. model, which conservatively assumes that the response spectral acceleration is equal to $S A_{\max }$ at the zero natural period.

(c) A constant maximum pseudo response spectral velocity $\left(S V_{\max }\right)$ occurs between the natural period limits of $T_{1}$ and 


\begin{tabular}{|c|c|c|c|c|c|c|c|}
\hline Models & $S A_{\max }$ & $S V_{\max }$ & $S D_{\max }$ & $T_{A}: S$ & $T_{\mathrm{B}}: \mathrm{S}$ & $T_{1}: \mathrm{s}$ & $T_{2}: \mathrm{s}$ \\
\hline Newmark and Hall ${ }^{14}$ (mean) & $2 \cdot 12 \mathrm{PGA}$ & 1.65 PGV & 1.39 PGD & 0.03 & 0.12 & 0.5 & $3 \cdot 0$ \\
\hline Newmark and Hall (mean + ISD) & $2 \cdot 7 \mid \mathrm{PGA}$ & $2 \cdot 30 \mathrm{PGV}$ & $2 \cdot 01 \mathrm{PGD}$ & 0.03 & $0 \cdot 12$ & 0.5 & $3 \cdot 0$ \\
\hline Somerville et al. ${ }^{27}$ & 1.85 PGA & $1 \cdot 80$ PGV & 1.75 PGD & 0.04 & $0 \cdot 10$ & $0 \cdot 3$ & 0.7 \\
\hline Lam et al. 8,9 & 3.0 EPGA & $2 \cdot 0 \mathrm{EPGV}$ & 1.0 EPGD & - & - & $0 \cdot 1-0.3$ & $0 \cdot 5-1 \cdot 5$ \\
\hline
\end{tabular}

Table I. Key parameters defining the response spectra (Fig. 8(b) refers)

$T_{2} . S V_{\max }$ is about $1.5-2.5$ times the peak ground velocity (PGV), according to the various models.

(d) A constant maximum pseudo response spectral displacement $\left(S D_{\max }\right)$ occurs in the range of natural period exceeding $T_{2} . S D_{\max }$ is about one to two times the PGD, according to the Newmark-Hall and Somerville et al. models. However, PGD is very difficult to determine from a strong motion accelerogram, and the manner in which PGD has been obtained in those studies has not been described in the literature. In the CAM model developed by the authors, ${ }^{3,8,9}$ EPGD is by definition equal to the maximum SD in the period range $0-T_{\mathrm{e}}$, with $T_{\mathrm{e}}$ defined earlier as $5 \mathrm{~s}$. It should be noted that the displacement demand threshold depends also on the impedance contrasts below the ground surface causing resonance to occur. Resonance can occur in both rock and soil, as previously discussed.

(e) Although the response spectrum should converge to the PGD at a very long natural period, the convergence has been conservatively ignored in the presented models. Except for rare, very long period structures, this is of no practical consequence.

In summary, the trilinear spectrum model shown in Fig. 8(a) is generally consistent with the models obtained independently by Somerville et al. ${ }^{27}$ and Newmark and Hall. ${ }^{14}$ The individual properties and interrelationships between the acceleration, velocity (pseudo-velocity) and displacement response spectra are summarised in Fig. 9. Note that, unlike Fig. 8, the response spectral amplitude and period scales in Fig. 9 are linear. Response spectrum modelling enables the key ground motion parameters to be estimated, by examining the relationship between the peak spectral responses and the peak effective ground motions for acceleration (short period range), velocity (intermediate periods) and displacement (long periods). For example, from analysis of a large number of earthquake response spectra from actual records and from synthetically generated records, ${ }^{28}$ it has been found that the peak response spectral acceleration, $R S A_{\text {peak }}$, within the flat part of the spectrum $\left(T<T_{1}\right)$ may be related to the effective peak ground acceleration (EPGA) by the relationship

$R S A_{\text {peak }}=3 \cdot 0 E P G A$

as shown in Fig. 9(c). Alternatively, $R S A_{\text {peak }}$ can be obtained in accordance with the value of the corner period, $T_{1}$, which is defined by

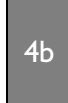

$$
T_{1}=\frac{0 \cdot 42}{\frac{A}{V}}
$$

where $A / V=E P G A / E P G V$ is in the common units $g /(\mathrm{m} / \mathrm{s})$, and $E P G V$ is the effective peak ground velocity, as defined later.

Similarly, the peak response spectral velocity, $R S V_{\text {peak }}$, defining the flat (constant) part of the velocity spectrum may be related to EPGV using the approximate relationship
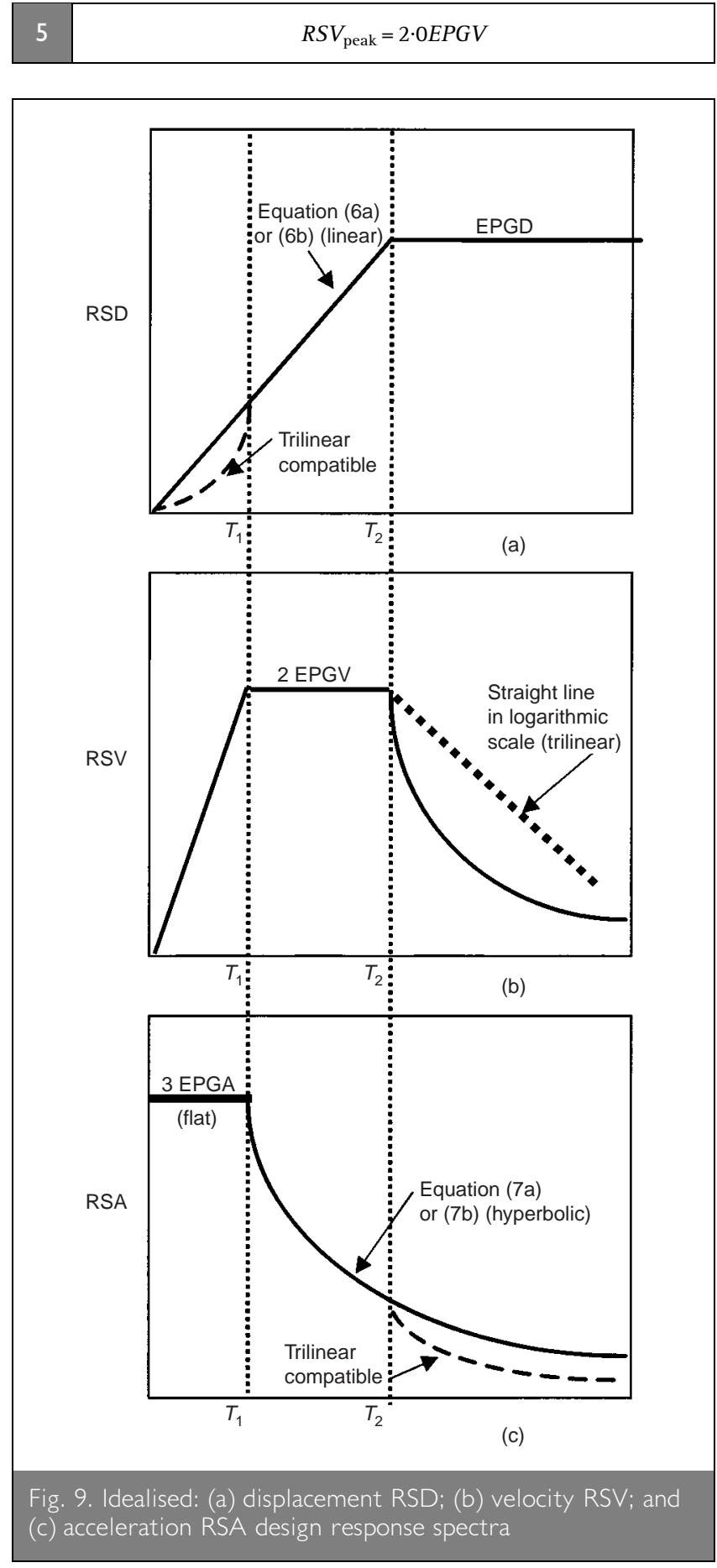
To ensure compatibility between the velocity and displacement spectra, the corresponding displacement response spectrum should be presented in the bilinear form with the key corner period being $T_{2}$, as shown in Fig. 9(a). The peak response spectral displacement within the flat part of the displacement spectrum can be taken to be equal to the EPGD, while the sloping (rising) part is defined by the expression

\begin{tabular}{|l|l|}
\hline $6 \mathrm{a}$ & $R S D=\left(\frac{R S V_{\text {peak }}}{2 \pi}\right) T$ \\
\hline
\end{tabular}

or

\begin{tabular}{|c|c|}
\hline $6 \mathrm{~b}$ & $R S D=\left(\frac{2 \cdot 0 E P G V}{2 \pi}\right) T$ \\
\hline
\end{tabular}

Alternatively, the sloping part of the spectrum can be obtained in accordance with the value of the corner period, $T_{2}$, which is defined by

\begin{tabular}{|l|l|}
\hline $6 c$ & $T_{2}=\left(\frac{2 \pi}{2 \cdot 0}\right) \frac{E P G D}{E P G V}=3 \cdot 15 \frac{E P G D}{E P G V}$ \\
\hline
\end{tabular}

where, for example, EPGD and EPGV have units of mm and $\mathrm{mm} / \mathrm{s}$, respectively.

In situations where resonance (in rock or soil) causes the RSD to significantly exceed the PGD, the EPGD can be conservatively defined as the peak RSD at the period of resonance.

Finally, the corresponding response acceleration spectrum should be represented in the usual flat-hyperbolic form, as shown in Fig. 9(c). The hyperbolic part, which is strictly applicable only between the two corner periods $T_{1}$ and $T_{2}$, is defined by the expression

\begin{tabular}{|l|l|}
\hline $7 \mathrm{a}$ & $R S A=2 \pi \frac{R S V_{\text {peak }}}{T}$ \\
\hline
\end{tabular}

or

\begin{tabular}{|l|l|}
\hline $7 \mathrm{~b}$ & $R S A=2 \pi\left(\frac{2 \cdot 0 E P G V}{T}\right)$ \\
\hline
\end{tabular}

Based on the trilinear spectrum illustrated in Fig. 8(a), it may be observed that the bilinear shape adopted for the design displacement response spectrum in Fig. 9(a) is compatible in the medium- and long-period ranges. However, in the short-period range the trilinear compatible displacement spectrum becomes the parabolic curve shown as the dotted line in Fig. 9(a), and hence by simplifying the RSD spectrum to the bilinear form the design displacement predictions for the short-period range $\left(T<T_{1}\right)$ become overly conservative. This is of little practical significance, however, as for such short period systems design may be based more appropriately on FB principles, using the flat part of the RSA spectrum (Fig. 9(c)). Correspondingly, the trilinear compatible RSA spectrum in the long-period range $\left(T>T_{2}\right.$ ), given by the dotted line in Fig. 9(c), indicates the conservatism of the hyperbolic part of the RSA spectrum in representing larger-than-expected displacement demands for long-period systems. As mentioned earlier, this latter feature has been recognised ${ }^{19,24}$ as a serious defect of present codified seismic design spectra expressed simply in terms of RSA, and is a motivating factor in separating the individual spectra as in Fig. 9.

\section{INELASTIC RESPONSE SPECTRA AND THE CAPACITY RESPONSE SPECTRUM}

In the past five years, new analysis and design procedures have been developed for the performance-based seismic analysis, design and rehabilitation of buildings. These procedures fall into the broad categories of DB methodologies, ${ }^{16,19,20,23-26}$ PB approaches $^{5,6,17,21}$ and the CS method. ${ }^{5}$ The PB and CS methods, in particular, are beginning to be integrated into the new generation of seismic codes ${ }^{6,29}$ and a simplified form of PB design is already incorporated into the New Zealand standard. ${ }^{17}$ Each of these approaches attempts to model the behaviour of structural systems undergoing both elastic and, in most instances, inelastic seismic response.

The relationship between elastic and inelastic response spectra is complex and the basic theoretical principles have been covered extensively elsewhere. ${ }^{1,4,14,18}$ Essentially, the procedures involve the modification of the elastic response spectrum using so-called force reduction factors (often given the notation $R$-factors) which are intended to account for the combined effects of period shifting (stiffness reduction), increased damping due to inelastic hysteretic element response and possible strength degradation. The representation of inelastic response spectra has been further advanced by the popular CS technique, which relates seismic capacity (as an inelastic force-displacement relationship, the force being equivalent to seismic acceleration) to demand, with the latter represented in terms of both seismic acceleration and displacement response spectra plotted simultaneously against each other. Such a representation permits the relative assessment of demand and capacity, and emphasises the critical parts of the earthquake response spectrum for any particular design application. The effect on seismic demands arising from period changes undergone by the structure during the seismic response are also explicitly tracked by the CS, wherein fixed period values are represented by radial lines centred at the origin of the force (acceleration)-displacement graph.

\section{CONCLUSIONS}

In this paper, the acceleration, displacement and velocity response spectra and their associated FB and DB assessment approaches have been reviewed, with particular reference to their physical interpretations. The mutual compatibility between the different response spectra was addressed and a unified trilinear response spectrum model defined by the parameters EPGA, EPGV and EPGD has been introduced. It has been emphasised that effective seismic analysis or design using response spectra relies on understanding both the physical processes of response to ground motions as well as the limitations of any single spectrum parameter in representing the overall response behaviour, especially when adopting a displacement-based or performance-based approach to seismic design or assessment.

\section{ACKNOWLEDGEMENTS}

The methodologies and procedures described in this paper have been developed as part of a project funded by the Australian Research Council (large grant), entitled 'Earthquake design parameters and design methods for Australian conditions' 
(AB89701689). This support is gratefully acknowledged. The support of the University of Hong Kong, through its CRCG Grant $14100 / 323 / 01$, is also gratefully acknowledged.

\section{REFERENCES}

1. Chopra A. K. Dynamics of Structures, Theory and Applications to Earthquake Engineering. Prentice-Hall, New Jersey, 1995.

2. Hu Y. X., LiU S. C. and Dong W. Earthquake Engineering. E and FN Spon, London, 1996.

3. Chandler A. M., Lam N. T. K., Wilson J. L. and Hutchinson G. L. Response spectrum modelling for regions lacking earthquake records. Canadian Journal of Civil Engineering, submitted September 2000.

4. PAZ M. International Handbook of Earthquake Engineering, Codes, Programs and Examples. Chapman and Hall, New York, 1994.

5. Whittaker A., Constantinou M. and Tsopelas P. Displacement estimates for performance-based seismic design. Journal of Structural Engineering, ASCE, 1998, 124, No. 8, 905-912.

6. Fajfar P. and Krawinkler H. (eds). Seismic Design Methodologies for the Next Generation of Codes. A. A. Balkema, Brookfield, VT, 1997.

7. Crouse C. B. and McGuire J. W. Site response studies for purpose of revising NEHRP seismic provisions. Earthquake Spectra, 1996, 12, No. 3, 407-439.

8. Lam N. T. K., Wilson J. L., Chandler A. M. and Hutchinson G. L. Response spectral relationships for rock sites derived from the component attenuation model. Earthquake Engineering and Structural Dynamics, 2000, 29, 1457-1489.

9. Lam N. T. K., Wilson J. L., Chandler A. M. and Hutchinson G. L. Response spectrum modelling for rock sites in low and moderate seismicity regions combining velocity, displacement and acceleration predictions. Earthquake Engineering and Structural Dynamics, 2000, 29, 14911525.

10. AtKinson G. and Silva W. An empirical study of earthquake source spectra for Californian earthquakes. Bulletin of the Seismological Society of America, 1997, 87, 97-113.

11. AtKinson G. M. and Boore D. M. Evaluation of models for earthquake source spectra in eastern North America. Bulletin of the Seismological Society of America, 1998, 88, No. 4, 917-934.

12. International Conference of Building OfFicials. Uniform Building Code, 1997 edition. International Conference of Building Officials, Whittier, CA, 1997.

13. Department of Buildings, The City of New York. The New York City Building Code, 1995 edition. Local Law 17/95, New York City, 1995.

14. Newmark N. M. and Hall W. J. Earthquake Spectra and Design. Earthquake Engineering Research Institute Monograph Series, Monograph No. 3, EERI, Berkeley, California, 1982.

15. EUROPEAN COMmitTEe For StANDARDISATION. Eurocode EC8: Structures in Seismic Regions; Part 1, General design and building. European Committee for Standardisation, 1994 (and national standards institutions), ENV 1998-1-1.

16. PRIESTley M. J. N. Displacement-based seismic assessment of existing reinforced concrete buildings. Proceedings of the 5th Pacific Conference on Earthquake Engineering, Melbourne, 1995, 225-244.

17. New Zealand Standard. Code of Practice for General Structural Design and Design Loadings for Buildings. Standards New Zealand, 1994, NZS 4203: 1984.

18. Воотн E. D. Concrete Structures in Earthquake Regions: Design and Analysis. Longman Scientific \& Technical, Harlow, 1994.

19. Calvi G. M. and Pavese A. Displacement based design of building structures. Proceedings of the 5th SECED Conference: European Seismic Design Practice, Research and Application, Chester, 1995, 127-132.

20. EdWARds M., Wilson J. L., LAM N. T. K. and Hutchinson G. L. The displacement based approach from an intraplate perspective. Proceedings of the Australasian Structural Engineering Conference, Auckland, 1998, pp. 713-720.

21. Structural Engineers Association of California (SEAOC): Vision 2000 Committee. Performance Based Seismic Engineering of Buildings. (Soulages J. (ed.)). SEA0C, Sacramento, 2 vols.

22. Earthquake Engineering Field Investigation Team. The Hyogo-Ken Nanbu (Kobe) Earthquake of 17 January 1995. A Field Report by EEFIT. EEFIT, Institution of Structural Engineers, London, 1997.

23. TSAngaris M. and ChAndLer A. M. A global analysis of earthquake displacement response spectra. Proceedings of the 6th SECED Conference: Seismic Design Practice into the Next Century, Oxford, 1998, 253-260.

24. Bommer J. J. and Elnashai A. S. Displacement spectra for seismic design. Journal of Earthquake Engineering, 1999, 3, No. 1, 1-32.

25. Chandler A. M., Tsangaris M., Lam N. T. K., Wilson J. L., EDWARDS M. and HuTChINSON G. L. Seismic performance of RC structures using displacement based principles. Proceedings of the 11th European Conference of Earthquake Engineering, Paris, 1998 (on CD-ROM), 12 pp.

26. EdWards M., Lam N. T. K., Wilson J. L. and Hutchinson G. L. The prediction of earthquake-induced displacement demand of buildings in Australia: an integrated approach. Proceedings of the New Zealand National Society of Earthquake Engineering (NZSEE) Conference, Rotorua, 1999, pp. $43-50$.

27. Somerville M., McCue K. and Sinadinovski C. Response spectra recommended for Australia. Proceedings of the Australasian Structural Engineering Conference, Auckland, 1998, pp. 439-444.

28. LAM N. T. K., WiLSON J. L. and Hutchinson G. L. Generation of synthetic earthquake accelerograms based on the seismological model: a review. Journal of Earthquake Engineering, 2000, 4, No. 3, 321-354.

29. Peer Center News. Advancing performance-based earthquake engineering. Pacific Earthquake Engineering Research Center Newsletter, 1999, 2, No. 1, 1-6.

Please email, fax or post your discussion contributions to the secretary: email: sismey_h@ice.org.uk; fax: +44 (0)20 7799 I325; or post to Helen Sismey, Journals Department, Institution of Civil Engineers, I-7 Great George Street, London SWIP 3AA. 